\title{
An unusual cause of variceal haemorrhage in an elderly patient
}

\author{
K. W. SOMERVILLE \\ M.B., F.R.A.C.P. \\ I. D. ANSELL \\ M.B., M.R.C.Path.
}

R. V. BOYD

M.B., M.R.C.P.

C. B. WILLIAMS

M.B., F.R.C.S.

\author{
G. D. BELL \\ M.D., M.R.C.P.
}

City Hospital, Nottingham NG5 IPB and Sherwood Hospital, Nottingham NG5 IPD

\begin{abstract}
Summary
An elderly patient with nodular regenerative hyperplasia of the liver and hypothyroidism who presented with life-threatening bleeding from oesophageal varices is discussed. Progress has been uneventful following a semi-emergency portocaval shunt 5 years ago with no evidence of hepatic encephalopathy. This is presumably a tribute to the relatively wellpreserved hepatic function in this condition.
\end{abstract}

KEY wORDS: nodular hyperplasia of liver, varices, portocaval shunt, hypothyroidism.

\section{Introduction}

Portocaval anastomosis for bleeding varices is relatively contraindicated in the elderly because of the high postoperative mortality and the fear that the procedure will precipitate postoperative encephalopathy. We report an elderly patient who has done surprisingly well following such a procedure; presumably a result of well-preserved hepatic function in association with a rare liver disorder, nodular regenerative hyperplasia.

\section{Case report}

A 69-year-old spinster presented in early 1978 with a 3-month history of non-specific 'failure to thrive'. She was found to be clinically and biochemically myxoedematous. Increasing dose thyroxine replacement was begun with subsequent good control of her hypothyroidism. However, her haematological indices were abnormal: haemoglobin $6.4 \mathrm{~g} / \mathrm{dl}$, MCV 99 $\mathrm{fl}$; white cell count $5.3 \times 10^{9} / 1$. Absent iron staining of the bone marrow indicated iron deficiency in the context of a hyperactive normoblastic marrow.

On examination there were no signs of liver disease or heart failure. Liver function tests were deranged, bilirubin $10 \mu \mathrm{mol} / 1$ (normal 5-17 $\mu \mathrm{mol} / 1$ ); alkaline phosphatase $220 \mathrm{iu} / 1$ (normal 46-190); alanine amino $c$ transferase (SGPT) $12 \mathrm{iu} / 1$ (normal 2-21); gammaglutamyl transpeptidase $70 \mathrm{iu} / 1$ (normal 4-18); albu- $\vec{\oplus}$ $\min 32 \mathrm{~g} / \mathrm{l}$; protein $63 \mathrm{~g} / \mathrm{l}$; one stage prothrombin $\propto$ time $13 \mathrm{~s}$ (control $13 \mathrm{~s}$ ). A barium swallow demonstrated oesophageal and gastric fundal varices, bleeding from which was thought to cause her iron deficiency. A scintigraphic liver scan showed a reduced uptake in a normal sized liver and increased

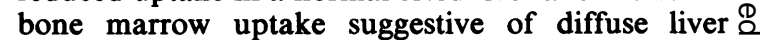
disease; the spleen was slightly enlarged. Anti- $\overrightarrow{\vec{\partial}}$ mitochondrial antibody and hepatitis B surface antigen tests were negative, anti-smooth muscle $\rightleftharpoons$ antibody was positive at a titre of 1:400. A provisional diagnosis of well-compensated cryptogenic $\frac{\overrightarrow{0}}{0}$ cirrhosis with portal hypertension was made and 3 further investigations were not thought appropriate. Transfusion and oral iron corrected the anaemia.

After 4 months of good progress she presented with 8 a haematemesis followed by melaena. She was not $₹$ jaundiced, shocked or encephalopathic and physical $\frac{\rho}{5}$ examination was unchanged. Endoscopy confirmed the oesophageal varices, and did not identify any other potential source of upper gastrointestinal $N$ haemorrhage. The bleeding stopped spontaneously o and she was again transfused. Despite the recurrent $\tilde{O}$ gastrointestinal bleeds her liver function remained N good, her serum albumin was well maintained, and $O$ she developed neither abdominal ascites nor signs of ${ }_{0}^{2}$ impending hepatic pre-coma. She was therefore $\frac{0}{\varnothing}$ considered a possible candidate for a portocaval $\stackrel{\infty}{\rightarrow}$ shunt operation. A coeliac axis arteriogram with 0 delayed views confirmed that the portal vein was patent. After a further large variceal bleed a semi- $\mathbb{D}$ urgent portocaval shunt was performed. 


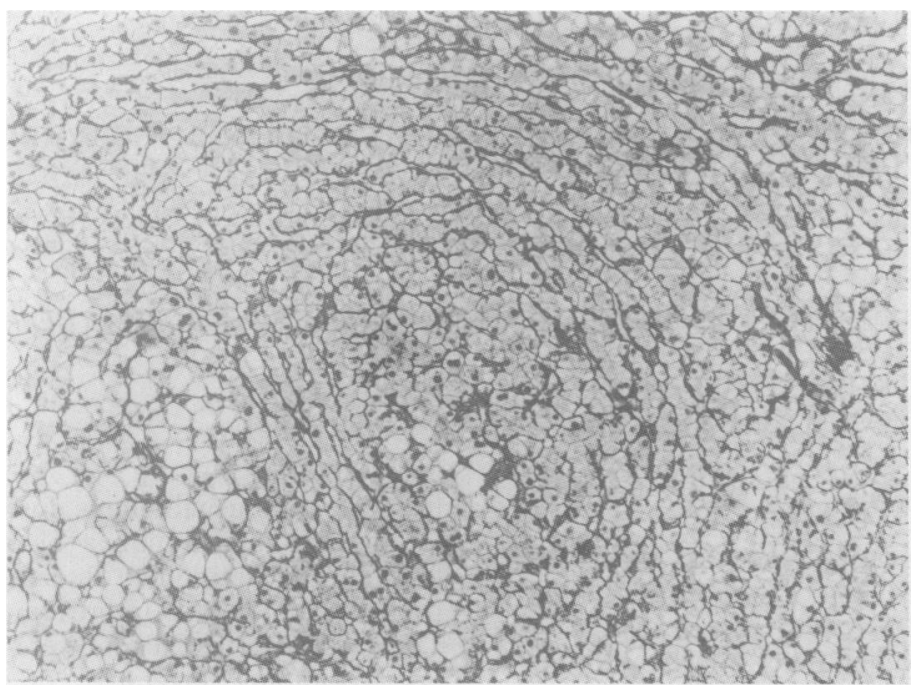

FIG. 1. Liver biopsy. Central group of hyperplastic hepatocytes compresses more peripheral attenuated liver cell plates but there is no fibrosis or cirrhosis. Modified Gordon and Sweet method for reticulin fibres $(\times 90)$.

At operation the liver was noted to be finely nodular rather than frankly cirrhotic; a subcapsular hepatic wedge biopsy was taken. Her postoperative course was uneventful. Her haemoglobin, platelet count, prothrombin time, liver function tests and albumin have remained normal and a barium swallow and meal 2 years postoperatively showed no evidence of varices. She has had no further overt gastrointestinal bleeding and there is no encephalopathy 5 years after surgery.

The operative liver biopsy (Fig. 1) showed no evidence of true cirrhotic nodule formation. The liver cell plates varied considerably in width with apparent central widened plates compressing peripheral attenuated plates. This appearance was thought typical of nodular regenerative hyperplasia.

\section{Discussion}

Nodular regenerative hyperplasia of the liver (NRHL) was first described in post-mortem material (Steiner, 1959), and subsequently in association with Felty's syndrome (Blendis et al., 1970), rheumatoid arthritis, congestive heart failure, CRST syndrome (Lurie et al., 1973), bacterial endocarditis (Knowles, Kaye and Goodman, 1975) and myelofibrosis (Shorey et al., 1979). Our patient had myxoedema associated with anti-smooth muscle antibodies. This may or may not be relevant although cases of NRHL have been reported without associated disease (Rougier et al., 1978).

The cause of NRHL is unknown and suggestions are merely speculative. For example, it has been suggested that the hepatic changes are secondary to splenomegaly but this seems most unlikely, in view of our patient's good response to shunt surgery. Like congenital hepatic fibrosis, NRHL produces portal hypertension with preservation of hepatocyte function and such cases are thus ideal candidates for portocaval anastomosis. Newer elective treatments for oesophageal varices such as injection sclerotherapy or propranolol may have an increasing future role in this situation, but we are impressed by the excellent results of the shunt procedure in this patient. Treatable forms of portal hypertension occur in the elderly and should be considered particularly in the context of good hepatic function. However, a standard closed needle biopsy usually yields a specimen on which a diagnosis of NRHL is difficult; an open biopsy is usually necessary for a definite diagnosis.

\section{References}

Blendis, L.M., ANSell, I.D., Lloyd Jones, K., Hamilton, E. \& Williams, R. (1970) Liver in Felty's syndrome. British Medical Journal, 1, 131.

KNOWLES, D.M., KAYE, G.I. \& Goodman, G.C. (1975) Nodular regenerative hyperplasia of the liver. Gastroenterology, 69, 746.

LURIE, B., Novis, B., BANK, S., SIlber, W., BOTHA, J.B.C. \& MARKS, I.N. (1973) CRST syndrome and nodular transformation of the liver. Gastroenterology, 64, 457.

Rougier, P., DegotT, C., RuefF, B. \& Benhamou, J.P. (1978) Nodular regenerative hyperplasia of the liver: Report of six cases and review of the literature. Gastroenterology, 75, 169.

SHOREY, J., WEINBERG, M.N., FrenKel, E.P. \& FALLIS, B.D. (1979) Nodular regenerative hyperplasia of the liver in a case of myelofibrosis with extramedullary haematopoiesis and secondary portal venous hypertension. American Journal of Clinical Patho$\log y, 72,122$.

STEINER, P.E. (1959) Nodular regenerative hyperplasia of the liver. American Journal of Pathology, 35, 943.

(Accepted 15 June 1983) 